\title{
Aportes de la Comisión Central de Señoras Cooperadoras Salesianas Argentinas al financiamiento del proyecto salesiano (Buenos Aires, 1900-1929)
}

\section{Financial contributions of the Comisión Central de Señoras Cooperadoras Salesianas Argentinas to the salesian project (Buenos Aires, 1900-1929)}

\author{
Lucía Bracamonte \\ Universidad Nacional del Sur (UNS), Bahía Blanca, Argentina. \\ luciab@criba.edu.ar |https://orcid.org/0000-0003-0198-9239
}

Recibido: 18 de febrero de 2019. Aprobado: 08 de agosto de 2020

DOI: $10.25100 /$ hye.v16i55.10870

Artículo de investigación

¿Cómo citar este artículo? / How to quote this article?

Bracamonte, Lucia. "Aportes de la Comisión Central de Señoras Cooperadoras Salesianas Argentinas al financiamiento del proyecto salesiano".(Buenos Aires, 1900-1929)". Historia y Espacio, vol. 16 n $^{\circ} 55$ (2020):49-72. DOI: 10.25100/hye.v16i55.10870 


\section{Resumen}

Desde fines del siglo XIX, las cooperadoras fueron importantes para conseguir recursos destinados a los proyectos de los salesianos y las Hijas de María Auxiliadora en la Argentina, ya fuera de manera individual o grupal. El objetivo específico de este artículo es analizar los ingresos monetarios de la Comisión Central de Señoras Cooperadoras Salesianas Argentinas entre 1900 y 1929, a fin de identificar la extensión de la asistencia proveída y las fuentes de financiamiento. Desde el análisis de esta entidad, aborda el problema de la relación entre los grupos confesionales femeninos y la intervención estatal en el área asistencial.

Palabras clave: Salesianos, Cooperadoras, Comisiones, Ingresos.

\section{Abstract}

Since the end of the 19th Century, the women cooperators were important to obtain financial resources, working individually or in group, for the projects of the salesians and the congregation Hijas de María Auxiliadora in Argentina. The main objective of this paper is to analyze the monetary income of the Comisión Central de Señoras Cooperadoras Salesianas Argentinas in the period 1900-1929, in order to determine the financial sources and the extension of the assistance provided. With the analysis of this entity, the relation between the confesional feminine groups and the State participation in the social assistance area is studied.

Keywords: Salesians, Cooperators, Commissions, Income. 


\section{Introducción}

Los religiosos de la congregación salesiana, creada en Turín por Juan Bosco en 1858, extendieron su accionar por Europa y América entre fines del siglo XIX y los albores del siglo XX. La Argentina fue el primer país americano al que arribaron, en 1875, debido, según señala Alejandra Landaburu, a varios factores: el interés por los numerosos extranjeros de origen piamontés y ligur, la presencia de familiares de salesianos, las buenas relaciones con las autoridades diplomáticas de Italia y Argentina y la posibilidad de una expansión misional que se extendería a la Patagonia habitada por indígenas e inmigrantes italianos. ${ }^{1}$ Sin embargo, como afirman María Andrea Nicoletti e Iván Fresia, el ingreso a ese territorio provocó tensiones con la Iglesia metropolitana y el Estado argentino, que lo reafirmaban como perteneciente a una administración diocesana y como parte del Estado nacional. El presidente Julio A. Roca, tras la sanción de las denominadas "leyes laicas" y la expulsión del Delegado Apostólico Luis Matera, recibió a Juan Cagliero en calidad de Obispo salesiano pero no de Vicario apostólico como lo había proyectado Don Bosco. Por su parte, el Arzobispo de Buenos Aires Monseñor León F. Aneiros fluctuó entre el reconocimiento del Vicariato y el temor a la reacción estatal. ${ }^{2}$

En suma, las intenciones de auxiliar a las familias de inmigrantes italianos, educar a niños, niñas y jóvenes de la clase obrera y evangelizar a los "indios" o "salvajes" de la Patagonia y de las "pampas", todas ellas de acuerdo con el mandato de su fundador, guiaron los emprendimientos de los religiosos. Cuatro años después los siguieron las religiosas de María Auxiliadora, que también serían protagonistas de ese proceso expansivo. ${ }^{3}$ La obra desplegada tuvo una gran amplitud ya que comprendió, entre otras ejecuciones, la fundación de oratorios e instituciones educativas, la realización de misiones en el sur, la puesta en circulación de diversas publicaciones y la creación de centros de ex alumnos/as, círculos de obreros y batallones de exploradores. Hacia 1900, los religiosos contaban con 250 casas, lo cual muestra la velocidad de su radicación en distintos puntos del país. ${ }^{4}$

\footnotetext{
${ }^{1}$ Según lo establecían las Constituciones, la cabeza de la estructura de gobierno de la congregación era el rector mayor, bajo cuya jurisdicción se encontraban los inspectores, los directores de las casas y los visitadores. Empleamos el término religiosos pues estaba integrada tanto por sacerdotes como por coadjutores (hermanos) que, si bien no llevaban hábitos, realizaban votos de pobreza, castidad y obediencia, debían observar las reglas y preceptos y realizar el noviciado. Alejandra Landaburu, Niñez, juventud y educación. El proyecto salesiano en Tucumán. 1916-1931 (Tucumán: Edunt, 2012), 56, 66.

2 María Andrea Nicoletti, "La Patagonia como territorio en disputa: tensiones entre el Estado, la Iglesia y la Congregación salesiana por el espacio misionero". Revista Cultura y Religión Vol. VI, nº 1 (2012): 183-203, https://core.ac.uk/download/pdf/158834355.pdf; María Andrea Nicoletti e Iván Ariel Fresia, "Breve relación de las misiones de la Patagonia hecho el 29 setiembre de 1887. El militarismo patagónico. El General Villegas por el salesiano Antonio Ricardi". Corpus 4, n 1 (2014): s.p., http://corpusarchivos.revues.org/688.

${ }_{3}^{3}$ Posteriormente se expandieron hacia Uruguay, Brasil, Chile, Ecuador, Venezuela, Perú, México, Bolivia, Paraguay, El Salvador y Estados Unidos. La congregación Hijas de María Auxiliadora fue fundada por Don Bosco y María Dominga Mazzarello en Mornese en 1871.

${ }^{4}$ Según Fortunato Mallimaci se convirtió en la principal congregación de toda la Argentina, dado que se propuso acompañar a los inmigrantes para integrarse desde la nueva religiosidad de la argentinidad católica y que hasta mediados del siglo XX prácticamente monopolizó el sistema educativo patagónico. Fortunato Mallimaci, El mito de la Argentina laica. Catolicismo, política y Estado (Buenos Aires: Capital Intelectual, 2015), 48-53.
} 
La labor salesiana requirió de un considerable sostén financiero que prácticamente no ha sido explorado, tanto por las dificultades de acceso a evidencias específicas como por los problemas que plantea su sistematización. Aunque no es posible reconstruir por completo la organización económica de una congregación de tamaña envergadura y dinamismo, pueden efectuarse análisis parciales que arrojen luz sobre algunas de sus facetas. Este trabajo focaliza a las cooperadoras, que desde el siglo XIX fueron engranajes importantes para la consecución de recursos, ya fuera de manera individual o formando parte de comisiones. Integraban la Pía Unión de Cooperadores Salesianos, entidad mixta de alcance internacional, que había sido creada por Don Bosco como una tercera orden y constituía, entre otras cosas, una forma de canalizar la beneficencia privada hacia la obra salesiana, atrayendo a personas de la elite que disponían de bienes materiales y gozaban de prestigio social e influencia política. ${ }^{5}$ El objetivo de este artículo es analizar los ingresos monetarios de la Comisión Central de Señoras Cooperadoras Salesianas Argentinas entre 1900 y 1929, a fin de identificar la extensión de la asistencia proveída y las fuentes de financiamiento. El periodo abordado se inicia con la gestión de la primera Presidenta efectiva Enriqueta Alais, durante la cual se estructuraron las modalidades de recaudación, y culmina antes del cambio de escenario económico que generaría la crisis de los años treinta. Alais ejerció el cargo desde la creación de la asociación hasta 1919 y la sucedieron Ernestina Bullrich (entre 1920 y 1922), María Delia Malbrán (desde 1922 hasta 1926) y Carmen Alvear (a partir de 1927).

Desde las dos últimas décadas del siglo XX existe un interés historiográfico creciente por las formas que adquirió el asistencialismo benéfico en la Argentina. La historia de las mujeres, línea en la que se inserta esta investigación, echó luz sobre la feminización del fenómeno al visibilizar asociaciones conducidas por mujeres de las clases altas que compartían espacios de sociabilidad, creencias y acceso a los detentadores del poder político. ${ }^{6}$ Sin embargo, aún no existe una visión de conjunto, resta realizar indagaciones sobre muchas instituciones y profundizar facetas como la financiera. Desde la historia social de la asistencia, Beatriz Moreyra señala que la reconstrucción de esta última permitiría valorar la capacidad y los límites de la racionalidad de la acción social en el marco de los constreñimientos estructurales, dentro de los cuales la subsidiariedad del Estado en materia social era crucial. ${ }^{7}$ La importancia de investigar el rol de los laicos y laicas y, en particular,

\footnotetext{
${ }^{5}$ Fue considerada por el Sumo Pontífice como una orden tercera pero con una finalidad no de piedad o devoción sino de apostolado, especialmente con respecto a la juventud en peligro. La integraban personas desde los dieciséis años con buena reputación religiosa y civil, que no realizaban votos religiosos ni vida comunitaria, eran nombradas por el rector mayor y debían guiarse por un reglamento confeccionado por Don Bosco en 1876. Sobre el "culto" a la figura cooperador en Córdoba, que implicaba rituales destinados a ensalzarla públicamente, véase: Nicolás D. Moretti, Buenos cristianos y honrados ciudadanos. La obra salesiana y la cuestión social. Córdoba, 1905-1930 (Córdoba: CEH, 2014).

${ }^{6}$ Para un panorama historiográfico véase: Beatriz I. Moreyra, "Modelo asistencial e historiografía en Argentina en la modernidad liberal”. Quinto Sol 21, n 3 (2017): 1-25, http://dx.doi.org/10.19137/qs.v21i3.1448.

${ }^{7}$ Beatriz I. Moreyra, "La cuestión social y las instituciones de protección social en la modernidad liberal: una relectura hermenéutica de las fuentes institucionales" en Las fuentes documentales en la historia social latinoamericana, comp. Fernando J. Remedi (Córdoba: Centro de Estudios Históricos Prof. Carlos S.A. Segreti, Red Internacional de Historia Social, 2015), 76-77.
} 
sus "inversiones" en lo "sagrado" a través de fuentes económicas y de gestión cotidiana, ha sido subrayada también por la historiografía religiosa. ${ }^{8}$

En una investigación que toma en cuenta indicadores financieros, Cecilia Tossounian señala que ciertas entidades de la Capital Federal ligadas al catolicismo que se ocupaban de mujeres e infantes en situaciones vulnerables ejercieron una fuerte influencia en el diseño y concreción de políticas sociales, convirtiéndose en la "faz maternal" del Estado hasta bien entrada la década del treinta. Desde su perspectiva, a diferencia de lo sucedido en países como Uruguay y Chile, su eficacia contribuyó a ralentizar la cristalización del Estado benefactor, a la que se llegaría a mediados del siglo XX. ${ }^{9}$ Esto entronca con la cuestión del aumento de la presencia de mujeres en el movimiento católico sobre todo en el decenio de 1920, respondiendo al llamado de la Iglesia para comprometerse en la lucha por la "recristianización" de la sociedad. Esa intervención pública es un indicador que relativiza aún más el ya matizado mito historiográfico de la Argentina laica, sustentado en la idea de que en la década de 1930 una única nación católica, orgánica y nacionalista reemplazó a una sólida y única república laica, democrática y liberal. ${ }^{10} \mathrm{El}$ presente artículo aspira a contribuir, desde el análisis de una entidad particular, a la elucidación del problema de la relación entre los agrupamientos confesionales conducidos por mujeres y la intervención estatal sobre el área del asistencialismo. ${ }^{11}$

Las fuentes centrales de esta investigación pueden tipificarse como institucionales, tanto por su ubicación archivística como por su factura, productores/as y destinatarios. Entre ellas se cuentan los balances confeccionados por las autoridades de la Comisión Central entre 1918 y 1929, que han sido localizados en el Archivo Central Salesiano de Buenos Aires. No se han encontrado los balances anteriores, ni los libros de caja y de actas, pero sí recibos, notas, correspondencia y otros documentos que permiten una contextualización de esos arqueos y una reconstrucción del panorama financiero previo, algunos de los cuales fueron relevados en el Archivo Salesiano Patagónico de Bahía Blanca.

\footnotetext{
${ }^{8}$ Según Roberto Di Stéfano y Aliocha Maldavsky, el vocablo "invertir" alude las dimensiones materiales y a la vez e inescindiblemente espirituales, sociales, políticas y afectivas de la participación activa de los laicos en la vida económica de las instituciones religiosas. El vocablo "sagrado" hace hincapié en el papel de la institución religiosa, capaz de transformar, a través de su mediación, el dinero, lo profano, lo material, en una entidad separada y muchas veces inalienable, o sea, sagrada. Roberto Di Stefano y Aliocha Maldavsky Invertir en lo sagrado: salvación y dominación territorial en América y Europa: siglos XVI-XX (Santa Rosa: Universidad Nacional de La Pampa, 2018), 9-10.

${ }^{9}$ Cecilia Tossounian, "Las Asociaciones Femeninas y la Emergencia de un Estado Social: La Protección a la Maternidad y a la Infancia (Buenos Aires 1920-1940)". Estudios Sociales del Estado Vol. 1/2 (2015): 58-93, http://estudiossocialesdelestado.org/index.php/ese/article/view/56. Sobre los aportes estatales al campo benéfico y las dificultades de sistematización véase: Donna J. Guy, Las mujeres y la construcción del Estado de Bienestar. Caridad y creación de derechos en Argentina (Buenos Aires: Prometeo Libros, 2011).

${ }^{10}$ Mallimaci, El mito de la Argentina laica, 25.

${ }^{11}$ Según Moreyra una mirada a largo plazo muestra que el denominado Estado de Compromiso fue el resultado de una construcción histórica realizada desde los tiempos coloniales por instituciones públicas y privadas con una progresiva y creciente participación del Estado. Beatriz Moreyra, "Modelo asistencial e historiografía en Argentina en la modernidad liberal", 3 .
} 
Desde una perspectiva de género y combinando aproximaciones cualitativas y cuantitativas, describiremos someramente las características de la elite con la cual los salesianos establecieron alianzas, a partir de las trayectorias biográficas de las autoridades de la Comisión, para pasar luego a focalizar los ingresos de la Comisión. ${ }^{12}$ En relación con estos últimos, analizaremos las actividades desarrolladas por las cooperadoras para cumplimentar su objetivo de sostener materialmente las obras, indagando el destino de los fondos e identificando los métodos prevalecientes de recaudación y la evolución de los principales rubros de entradas. Sostenemos que en la década de 1920 el Estado acrecentó progresivamente su aporte a la entidad por la necesidad de sitios para depositar a los/as menores de acuerdo a lo dispuesto en la legislación y a los ofrecimientos de las cooperadoras, como consecuencia de lo cual, si bien los tipos de ingresos no se modificaron, la contribución de la Comisión al accionar de la congregación se incrementó. Además, dicha ayuda monetaria siguió destinándose a diversos puntos del país, pese a que a mediados de ese decenio los religiosos recortaron normativamente el radio de acción de ese agrupamiento femenino, en el marco de una reestructuración de las inspectorías y de la cooperación salesiana organizada.

\section{Las autoridades de la Comisión Central: elite nacional y asistencialismo social}

Las cooperadoras salesianas actuaron en forma colectiva desde 1900, fecha de creación de la Comisión Central de Señoras Cooperadoras en la Capital Federal, dentro de la órbita de la Inspectoría San Francisco de Sales, con el propósito de auxiliar a los religiosos salesianos y a las Hijas de María Auxiliadora. ${ }^{13}$ Integraban una elite social que tenía gravitación nacional y estaba conformada, como señala Leandro Losada, por algunas familias de raíces coloniales, otras constituidas por inmigrantes arribados antes de 1880 y ciertos grupos parentales del interior del país. Luego de una etapa de consolidación hacia 1910, este sector sufriría una declinación paulatina como consecuencia de la reforma electoral de 1912 que relativizaría la lógica elitista, de las complicaciones de la economía agroexportadora durante la posguerra y de la cuasi estabilización de la producción agrícola ganadera y la aparición de la sociedad de masas desde fines de la década de $1920 .^{14}$

\footnotetext{
${ }^{12}$ Definimos el género como conjunto de funciones sexuadas y nociones sobre la femineidad y la masculinidad. Las definiciones sexuales especifican naturalezas o esencias para cada sexo y proyectan socialmente esa distinción en forma de ámbitos divididos dualmente y jerarquizados con predominio masculino. Rosa Cobo Bedia, "Otro recorrido por las ciencias sociales: género y teoría crítica" en Cuadernos de género: Políticas y acciones de género, ed. Marta Aparicio García et al. (Madrid: Universidad Complutense, 2009), 11-36.

${ }^{13}$ La Comisión estaba compuesta por presidentas honoraria y efectiva, secretaria, tesorera, al menos 25 vocales y un número variable de vicepresidentas, protesoreras y prosecretarias. Se conformó con 45 integrantes y veinte años después tenía 123. Además, había numerosas cooperadoras que integraban la Pía Unión a título individual, sin participar directamente en la Comisión. "Actas del II Congreso Internacional de Cooperadores Salesianos", Buenos Aires, 1900, en Archivo Central Salesiano (ACS) Buenos Aires-Argentina, pp. 24-26; Comisión Central de Sras. Cooperadoras Salesianas, Invitación, 15 de junio de 1920, en ACS.

${ }^{14}$ Leandro Losada, La alta sociedad en la Buenos Aires de la Belle Epoque (Buenos Aires: Siglo XXI, 2008).
} 
El parentesco establecido a partir de lazos matrimoniales fue uno de los mecanismos de constitución de esa elite, lo cual en el caso de las cooperadoras dirigentes se observa, por ejemplo, en el matrimonio entre Malbrán, que provenía de una familia tradicional porteña, y Enrique Vedoya, integrante de un núcleo familiar del interior del país. No solamente lazos familiares sino también de amistad enlazaban a estas personas que compartían un estilo de vida lujoso, sofisticado y ostentoso que incluía veraneos en estancias y en Mar del Plata, viajes a Europa, presentaciones de señoritas "en sociedad", visitas protocolares en "días de recibo" y la adopción de usos y costumbres de raíces europeas. En este contexto, la actuación de Celia Lapalma de Emery como tesorera durante largos años introduce un matiz, ya que si bien se encontraba integrada a este grupo y se reconocía en sus discursos públicos como miembro de las "clases pudientes"15, trabajó percibiendo un salario en el Departamento Nacional del Trabajo y en escuelas profesionales para mujeres.

Las redes económicas, trazadas a partir del protagonismo de los miembros de este sector en el modelo agroexportador, fueron otro elemento de aglutinación. Los esposos de Alais y María Larramendy eran terratenientes, Vedoya actuó como presidente de la Bolsa de Comercio, el padre de Bullrich fundó una casa de remates, administración de campos y comercialización de animales de raza y fue director del Banco Hipotecario, mientras que Federico Lacroze, el esposo de Ana Browne, fue un importante capitalista en el sector del transporte tranviario. Además, varios de ellos ocuparon cargos en la esfera política, como el mencionado Bullrich que accedió al puesto de intendente de Buenos Aires, Manuel M. de Iriondo, casado con María Salomé Freire, que actuó como secretario de un gobernador radical de la provincia homónima, diputado y ministro de Hacienda, y el primo de Alvear, que llegó a ser presidente de la república.

Además de interrelacionarse en la esfera de la sociabilidad informal, estas personas forjaron vínculos en espacios de sociabilidad formal de rasgos exclusivistas, algunos de tipo recreativo y otros en los que aunaron esfuerzos para hacer frente a problemáticas sociales. El deseo de consolidar su status y reputación, invertir en lo sagrado para lograr su salvación y aportar a la solución de la "cuestión social" impulsó a ciertos notables católicos -que apoyaban la conciliación con el Estado liberal- a contribuir con algunas entidades asistencialistas y legitimó la intervención en ellas de los sujetos femeninos de sus familias. Las cooperadoras contaban con el beneplácito de los varones de su entorno, en el que convivían católicos -algunos de los cuales también integraron grupos de cooperadores que tuvieron menor continuidad-, y liberales. ${ }^{16}$

La Comisión formaba parte de un área asociativa asistencialista de carácter heterogéneo, escasamente amalgamada y con poca planificación, que adquiría cierta consistencia porque

\footnotetext{
${ }^{15}$ Celia Lapalma de Emery, Acción pública y privada en favor de la mujer y del niño en la República Argentina, Buenos Aires, Alfa y Omega, 1910.

${ }^{16}$ Por ejemplo, Enrique Mosquera, el esposo de Bullrich, se inscribió como cooperador, Alberto J. Vivot, hijo de Alais, fue presidente de la Junta Asesora de las Misiones de la Patagonia e Iriondo y Vivot integraron como vocales el comité promotor del IX Congreso Internacional de Cooperadores Salesianos.
} 
en general los cargos dirigentes eran detentados por mujeres integrantes de la elite social. ${ }^{17}$ Lapalma y Anchorena fueron presidentas, Browne y Devoto tesoreras y Bullrich, Cirila Suárez, Leonor Cabral y Lucía P. de Duhalde integrantes de las Conferencias de Señoras de San Vicente de Paul. Anchorena y Bullrich participaron en la Liga Argentina de Damas Católicas, Malbrán formó parte de la Congregación Hijas de María y de la Comisión para la construcción de la escuela y el Patronato de la Infancia, Devoto actuó en las juntas de la Asociación Escolar Mutualista y del Patronato de la Infancia, mientras que Freire formó parte de la Comisión para la construcción del Colegio y Asilo Maternal del Bueno y Perpetuo Socorro. Además, varias de ellas estaban ligadas a la Sociedad de Beneficencia, como Mercedes Bullrich, Anchorena y Susana Casares, y otras como María Meyer Pellegrini proyectaban sus actividades a la Obra Stella Maris de Mar del Plata.

Si bien los emprendimientos salesianos eran diversos, las cooperadoras declaraban en discursos -atravesados por una retórica maternalista que concebía su accionar como una proyección de la naturaleza maternal femenina- que concentraban sus esfuerzos en iniciativas vinculadas al asilo, la educación y la evangelización de niñas, niños y jóvenes de los sectores populares, como se observa en las palabras de la tesorera Julia Coy: “... he tratado de aportar mi modesta cooperación a la Obra de Don Bosco con mi mayor empeño y cariño, pues su fin que va directo al bien de la niñez y juventud es a mi modo de ver uno de los más dignos de ayuda y protección". ${ }^{18}$ Desde fines del siglo XIX, la preocupación por la cuestión de la niñez en peligro por su desamparo y a la vez potencialmente peligrosa para el mantenimiento del orden social se había hecho sentir con fuerza en el país, especialmente en las ciudades que crecían de manera acelerada al compás de la modernización económica y social. La intervención sobre el universo de las infancias también caracterizaba a la Sociedad de Beneficencia, el Patronato de la Infancia, las Damas de la Caridad de San Vicente de Paul, la Sociedad de Misericordia y el Asilo Naval, entre otras instituciones de la Capital Federal que actuaban en colaboración con el Estado. La participación de este último estaba sujeta a vaivenes y muchas veces era subsidiaria pero no prescindente pues las proveía de recursos, en especial a las dos primeras. ${ }^{19}$

\footnotetext{
${ }^{17}$ Para profundizar las características del asociacionismo católico véase: Miranda Lida, Historia del catolicismo en la Argentina entre el siglo XIX y el XX (Buenos Aires: Siglo Veintiuno Editores, 2015).

18 "Informe General de la Comisión Central de Señoras Cooperadoras", Buenos Aires, 1927-1929, en ACS, p. 23.

${ }^{19}$ Desde 1880 la Argentina, conducida por gobiernos liberales en lo económico y conservadores en lo político, se insertó en el mercado mundial como exportadora de alimentos y materias primas, e importadora de manufacturas. La cantidad de habitantes aumentó aceleradamente por la inmigración masiva. Paralelamente al crecimiento económico se registró una preocupación en juristas, educadores y médicos por la "cuestión social", vinculada con la agitación obrera, el pauperismo, las enfermedades, el hacinamiento, la criminalidad, la prostitución y los niños y niñas huérfanos/as o abandonados/as a quienes se aplicaba la categoría "menor" para distinguirlos/as de quienes tenían una adecuada contención familiar, escolar y laboral. Sobre la Sociedad de Beneficencia, que era una agencia pública pero con gran autonomía administrativa véase: Valeria S. Pita, "Política, conflictos y consensos en torno al brazo asistencial del Estado argentino. La Sociedad de Beneficencia de la Capital, 1880-1910.", en Mujeres y Asistencia Social en Latinoamérica, siglos XIX y XX. Argentina, Colombia, México, Perú y Uruguay, comp. Yolanda Eraso (Córdoba: Alción, 2009), 95-130.
} 
Las autoridades de las comisiones directivas de todas estas instituciones realizaban un trabajo de carácter voluntario y no remunerado que les proporcionaba la satisfacción de realizar obras de caridad cumpliendo con sus deberes como católicas, reconocimiento social y oportunidades para ejercer poder. En lo que atañe particularmente a las cooperadoras, los religiosos y las religiosas eran conscientes de las ventajas que tenía la pertenencia de las dirigentes a la elite, como se aprecia en una misiva enviada por Vespignani en 1910 a la secretaria Freire, en la cual le solicitaba el "favor" de que intercediera ante su marido, que a la sazón era ministro de Hacienda, para que exonerara de tasas a un conjunto de cajones destinados al hospital de Viedma que se encontraban en la Aduana. ${ }^{20}$ La siguiente carta, dirigida en 1928 por la directora del Colegio María Auxiliadora de Viedma a la presidenta Alvear, también es sugerente al respecto:

"Nos encontramos en una necesidad apremiante, tratándose de pagar el agua corriente que, por efecto de un convenio entre el Gobierno Nacional y la Municipalidad de Viedma, sube, para nosotras, a la enorme suma de $\$ \mathrm{n} / \mathrm{n}$ 1.500 mil quinientos al año.

Como Ud. ve, un Colegio de María Auxiliadora como el nuestro, donde la casi totalidad de sus alumnas son huérfanas o muy pobres no puede satisfacer una suma así. Por eso, 'a Dios rogando y con el mazo dando' no hemos dejado de llamar a las puertas del Ministerio de Obras públicas solicitando un Decreto de exoneración del pago de agua. El último recurso que nos queda es el Excmo Señor Presidente de la Nación de quien hoy solicitamos dicho Decreto; pero para llegar hasta El necesitamos el apoyo de una persona que, como Ud., mire con cariño de madre a nuestras pobrecitas asiladas y a las Hijas de María Auxiliadora, y al mismo tiempo tenga influencia sobre el ánimo del Primer Magistrado..."21

A diferencia de otras asociaciones radicadas en la Capital Federal, las cooperadoras no tenían a su cargo la gestión directa de instituciones, pero el alcance de su accionar fue muy amplio, debido a la proyección de su auxilio hacia distintos puntos del país y especialmente hacia los territorios nacionales pampeano patagónicos. ${ }^{22}$ De acuerdo a lo estipulado en el Programa de la Comisión Auxiliar de Señoras Cooperadoras, el agrupamiento apoyaba los emprendimientos de los religiosos y las religiosas de todo el país, que como indicamos crecían en forma extraordinaria. En 1911 se creó la Inspectoría San Francisco Javier, lo cual no redundó de inmediato en una reorganización de la cooperación salesiana, como se observa en los cuadros estadísticos publicados en 1921 y 1923 a requerimiento del Estado, en los

\footnotetext{
20 "Carta de José M. Vespignani a Salomé Freire", Buenos Aires, 31 de enero de 1910, en ACS.

21 "Carta de Sor Josefina Picardo a Carmen Alvear", Viedma, 29 de septiembre de 1928, en ACS.

${ }^{22}$ La Pampa, Río Negro, Neuquén, Chubut, Santa Cruz y Tierra del Fuego eran espacios que se encontraban por fuera de los límites provinciales. Fueron creados primero como espacio nacional en bloque y luego, por la ley 1532 de 1884, como Territorios Nacionales. Sus autoridades eran designadas por el Poder Ejecutivo Nacional. Al reunir 30 mil habitantes tenían la posibilidad de constituir sus legislaturas y al alcanzar 60 mil pobladores podían convertirse en provincias. Al respecto véase: Martha Ruffini, La pervivencia de la República posible en los territorios nacionales. Poder y ciudadanía en Río Negro (Bernal: Universidad Nacional de Quilmes Editorial, 2007).
} 
cuales se incluía un detalle de los establecimientos socorridos por las cooperadoras capitalinas. $^{23}$ En estos impresos figuraban misiones, oratorios festivos, colegios y escuelas profesionales de artes y oficios y de agricultura de todo el territorio nacional. ${ }^{24}$ (Ver figura 01)

La reorganización de la cooperación salesiana se produjo en 1926, momento en que la Inspectoría San Francisco Solano o Norte con sede en Córdoba se desmembró de la Inspectoría San Francisco de Sales. En esa misma fecha se independizó de la Comisión Central una subcomisión de mujeres que había sido creada en 1920 para proteger a las "Misiones del Sud" y pasó a estar bajo la autoridad del inspector que estaba al frente de la Inspectoría San Francisco Javier. Además, durante la década del veinte se formalizaron otros grupos de cooperadoras en distintos puntos del país, como Córdoba, Tucumán, Bahía Blanca, Viedma, Puerto Pirámides, Eduardo Castex y Comodoro Rivadavia. Como consecuencia de todos estos procesos y de un conflicto suscitado entre las propias cooperadoras por la existencia de dos comisiones en Buenos Aires, se efectuó un recorte del radio de acción de la Comisión Central ciñéndolo a la Inspectoría, lo cual quedó plasmado en el Reglamento General de la Comisión Central de Señoras Cooperadoras Salesianas. ${ }^{25}$ Sin embargo, como veremos en el próximo apartado, el análisis de fuentes financieras muestra que su actividad excedió los límites de esta jurisdicción.

\footnotetext{
23 "Programa de la Comisión Auxiliar de Señoras Cooperadoras", Buenos Aires, s.f., en ACS, p. 22. La Inspectoría de San Francisco de Sales tenía jurisdicción sobre la parte norte del país y el territorio de La Pampa, y la de San Francisco Javier sobre la parte sur de la provincia de Buenos Aires y los territorios nacionales de Río Negro, Neuquén, Chubut, Santa Cruz y Tierra del Fuego.

${ }^{24}$ Los sitios señalados eran: Buenos Aires, Bernal „La Plata, Rosario, Córdoba, San Miguel de Tucumán, Salta, Rodeo del Medio, Eduardo Castex, Ensenada, General Acha, Guatraché, General Pirán, Mendoza, Ramos Mejía, San Nicolás de los Arroyos, San Isidro, Santa Rosa, Telén, Uribelarrea, Colonia Vignaud, Victorica, Avellaneda, Morón, Bahía Blanca, Fortín Mercedes, Viedma, Choele Choel, General Roca, Rawson, Trelew, Junín de los Andes, Comodoro Rivadavia Puerto Madryn y Río Gallegos.

25 José M. Vespignani, "Reglamento General de la Comisión Central de Señoras Cooperadoras Salesianas de Buenos Aires", s. f., en ACS
} 
Figura 01. Mapa de los establecimientos patrocinados por la Comisión Central

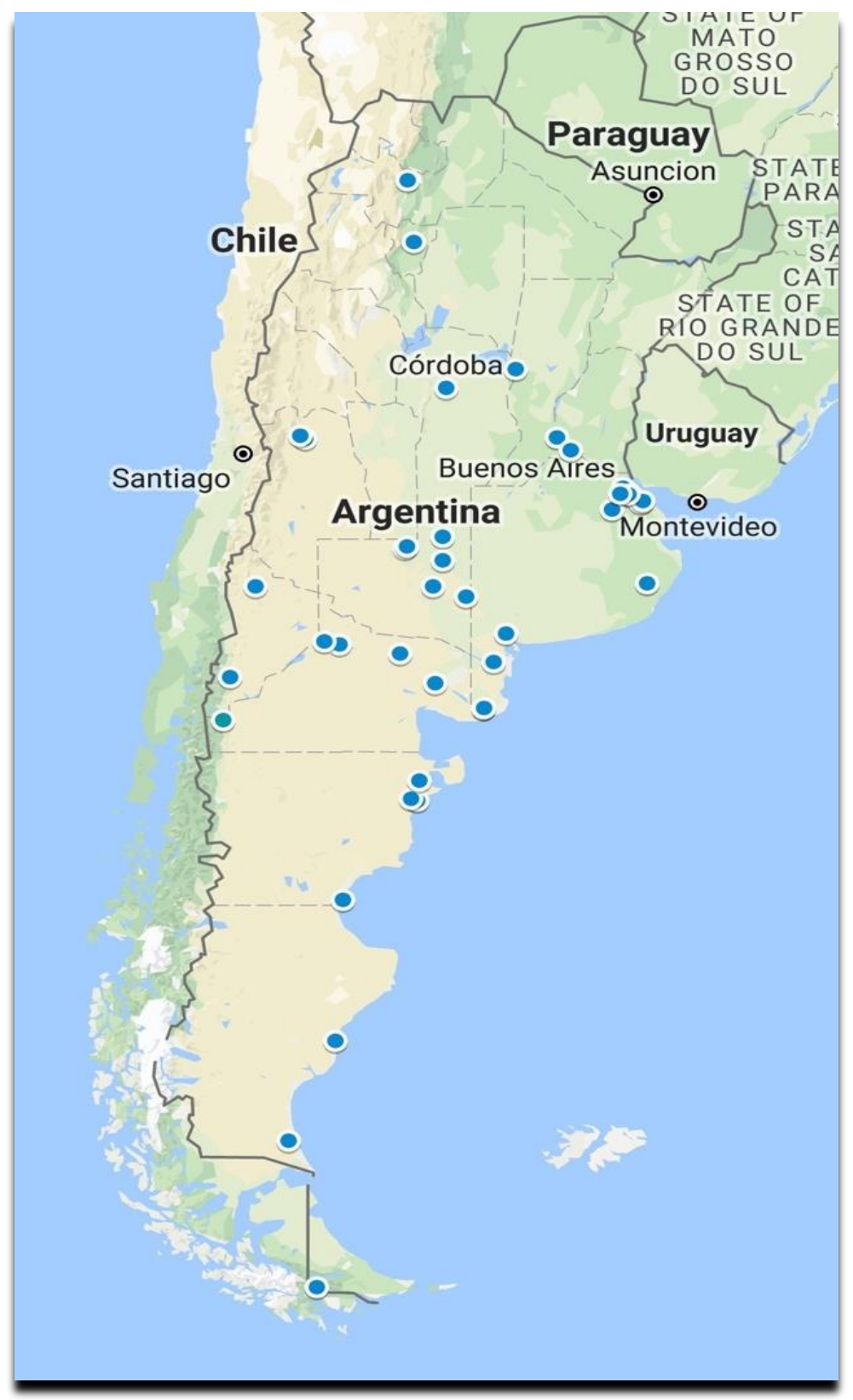

Fuente: elaboración propia en base a ACS, Cuadros Estadísticos de la Obra del Vble. Don Bosco en la República Argentina patrocinada por la Comisión de Señoras Cooperadoras Salesianas, Buenos Aires, 1921 y 1923 


\section{Funciones recaudadoras: composición y evolución de las fuentes de financiamiento}

Desde 1900, la Comisión dirigió sus esfuerzos a reunir dinero pero también a conseguir otros beneficios como exenciones impositivas y bienes materiales de distinto tipo. De acuerdo con lo pautado en la normativa internacional y nacional de la Pía Unión, sus autoridades debían comunicar los gastos en las reuniones y elaborar balances periódicos que especificaran las entradas y salidas. ${ }^{26}$ La presidenta, al inicio de su gestión, se interiorizaba del estado de las finanzas, para lo cual se apersonaba en las entidades bancarias, verificaba las cuentas corrientes y plazos fijos y solicitaba el cambio de nombre de las cuentas. La tesorera, con supervisión de la presidenta, registraba los ingresos y egresos, conservaba los comprobantes correspondientes y las libretas de banco, emitía cheques y recibos y se ocupaba de los depósitos. La secretaria, además de sus funciones específicas, también tenía una tarea de acompañamiento en las gestiones vinculadas con la consecución y administración de fondos. En consecuencia, todas ellas recibían y entregaban dinero, interactuaban con los bancarios y con el ecónomo o apoderado inspectorial y llevaban registro de los movimientos.

Los balances, firmados por la tesorera y la presidenta, daban cuenta anualmente de la gestión a los superiores de la congregación y eran revisados por el inspector y en ciertas ocasiones por un contador. Si bien los religiosos señalaban los errores, como sucedió en los arqueos correspondientes a los años 1919, 1927, 1928 y 1929, ello no hacía mella en su opinión laudatoria sobre las capacidades recaudadoras y administrativas de las cooperadoras. En 1929 el inspector cerraba su estudio del documento presentado con estas palabras: "Estas son simples observaciones de forma, como he dicho al principio, y no afectan en nada el resultado final, que se halla en perfecto acuerdo con los comprobantes y registros, llevados con prolijidad y exactitud." 27

Esas funciones conllevaban un alto grado de responsabilidad y también de riesgos, como se evidenció en una ocasión en la que Alais y sus compañeras fueron estafadas. ${ }^{28}$ También demandaban una considerable inversión de tiempo y debían ser articuladas con los roles domésticos y maternales que les asignaban las definiciones normativas de la femineidad. Estas prescripciones se aplicaban a las mujeres de todas las clases sociales, si bien su implementación en la práctica difería de acuerdo a los recursos, el número de hijos, el estilo de vida y el ciclo vital. Lapalma, como señalamos, era una excepción, ya que realizaba inspecciones para la Municipalidad de Buenos Aires y el Departamento Nacional del Trabajo y era profesora y directora de instituciones educativas, escritora y conferencista, además de esposa y madre. Al igual que Alais, Bullrich, Alvear, Browne, Larramendy y Sara Moreno de Gowland, desde 1920 era viuda, condición que marcaba una distinción con

\footnotetext{
26 "Manual teórico-práctico para uso de los decuriones y directores de la Pía Asociación de los cooperadores salesianos", Turín, Tipografía Salesiana, 1897, en ACS; "Programa de la Comisión Auxiliar de Señoras Cooperadoras", Buenos Aires, s. f., en ACS y Vespignani, "Reglamento General de la Comisión Central de Señoras Cooperadoras Salesianas de Buenos Aires".

27 "Carta de S.S.C y C. a Julia Coy", Buenos Aires, 23 de noviembre de 1929, en ACS. Véase también: "Carta de S.S.S. y C. a Celia Lapalma", Buenos Aires, 24 de diciembre de 1920, en ACS.

28 "Carta de Enriqueta Alais a José M. Vespignani", El Retiro, 30 de mayo de 1916, en ACS.
} 
respecto a las cooperadoras casadas, ya que desde el punto de vista jurídico se había establecido la incapacidad de hecho relativa de aquellas que habían contraído matrimonio y la representación necesaria de sus maridos en cualquier acto realizado en la esfera pública. ${ }^{29}$ En su accionar vinculado a la congregación tenían una ventaja legal de la que no disfrutaban en sus hogares, ya que podían tomar decisiones en cuanto al manejo de sumas cuantiosas, aunque supervisadas por los religiosos y con el permiso de sus cónyuges.

La Comisión Central tuvo varias fuentes de ingresos que se mantuvieron durante las tres décadas analizadas, una de las cuales fue el Estado en sus diferentes niveles. (Ver figura 02) Si bien no todas las asignaciones estatales a la congregación pasaban por la Comisión y varias de ellas eran previas a su constitución, es claro que este agrupamiento de mujeres fue una de las vías utilizadas para peticionar y tramitar dicho auxilio económico tanto ante los poderes ejecutivos como legislativos. El aporte estatal gestionado por las "damas" comprendía dinero que llegaba en la forma de becas y subsidios así como también otros beneficios entre los que se contaban exoneraciones de impuestos municipales para los inmuebles, exenciones del pago del adoquinado frente a los colegios de la provincia de Buenos Aires, rebajas en precios de alimentos y maderas, y donaciones de telas, mantas, vestimentas y plantas.

Figura 02. Cuadro comparativo de los ingresos de la Comisión Central de Señoras Cooperadoras Salesianas expresados en pesos moneda nacional.

\begin{tabular}{|c|c|c|c|c|c|}
\hline Año & Subsidios & Colectas & Donaciones & $\begin{array}{c}\text { Becas y } \\
\text { suscripciones }\end{array}$ & $\begin{array}{c}\text { Eventos y } \\
\text { rifas }\end{array}$ \\
\hline 1918 & 0 & 16958 & 11163 & 1941 & 7989 \\
\hline 1919 & 500 & 14296 & 11427 & 1903 & 2890 \\
\hline 1920 & 0 & 21390 & 5125 & 1371 & 6737 \\
\hline 1921 & 0 & 38733 & 16590 & 3583 & 619 \\
\hline 1922 & 14700 & 28974 & 22520 & 6376 & 1205 \\
\hline 1923 & 26500 & 18612 & 31574 & 6968 & 12409 \\
\hline 1924 & 26000 & 13661 & 21923 & 6857 & 5004 \\
\hline 1925 & 25867 & 4850 & 0 & 1647 & 0 \\
\hline 1926 & 19400 & 0 & 0 & 1381 & 0 \\
\hline 1927 & 8083 & 3300 & 10250 & 949 & 0 \\
\hline 1928 & 307778 & 16419 & 6821 & 2154 & 23238 \\
\hline 1929 & 145783 & 29404 & 590 & 1311 & 4458 \\
\hline
\end{tabular}

Fuente: elaboración propia en base a ACS, Balances de la Comisión Central de Señoras Cooperadoras Salesianas, Buenos Aires, 1918-1929.

\footnotetext{
${ }^{29}$ En 1926 se sancionó la ley 11.357 por la cual las solteras, viudas o divorciadas mayores de edad, pasaron a
} ser consideradas jurídicamente iguales a los varones, pero para las casadas subsistieron algunas incapacidades. 
En cuanto a las becas, a través de los balances no es posible precisar cuáles estaban sustentadas en aportes estatales y cuáles eran solventadas por particulares, ni diferenciarlas de las suscripciones junto con las cuales eran consignadas. ${ }^{30}$ Asimismo, resulta difícil detectar su destino específico en la columna de egresos, excepto en las ocasiones en las que se mencionaban establecimientos específicos como el Colegio León XIII del barrio de Almagro, los Colegios María Auxiliadora de Yapeyú y Victorica, la Escuela Taller de María Auxiliadora de Maldonado y el noviciado de Bernal.

Otro obstáculo para determinar su monto es que aquellas partidas que procedían del Ministerio de Justicia e Instrucción Pública se liquidaban a la orden del ecónomo y, en consecuencia, no se consignaban en los balances de la Comisión. Pese a ello, hubo un registro parcial a fines de la década del veinte bajo el rótulo "Subsidio para Menores", que puede haber obedecido a que las cooperadoras tramitaban su cobro ante las autoridades del Ministerio de Hacienda y a que formaban parte de la Comisión General de Sociedades para el Patronato de Menores, la cual había sido creada en consonancia con los lineamientos de la denominada Ley Agote. ${ }^{31}$ Esta norma incrementó la intervención estatal en el área de la minoridad y mantuvo un sistema de tutela en el que se combinaban las actuaciones de particulares (a través de la colocación en casas de familia), instituciones benéficas e instituciones oficiales como la Colonia de Menores Varones de Marcos Paz y el Instituto Tutelar de Menores de la Capital. En este contexto adquirieron gran importancia las becas, que en el caso de los salesianos se destinaban al sostenimiento parcial o completo de alumnos de los colegios agrícolas y de artes y oficios, entidades que sintetizaban las dos facetas del proyecto de la congregación: la asistencial, encaminada a la satisfacción de las necesidades básicas, y la promocional, centrada en la formación para el trabajo.

Las cooperadoras no solamente se ocupaban del cobro de las becas sino que, además, ofrecían vacantes, como sucedió en 1921 cuando pusieron a disposición del gobierno de la provincia de Buenos Aires 100 plazas en colegios de La Plata, San Nicolás, Uribelarrea, Pirán, Bahía Blanca y Patagones, señalando por medio de su presidenta: "Como cooperación del Estado a esta obra de verdadero patriotismo, solicito que él contribuya con una cuota de $45 \mathrm{~m} / \mathrm{n}$. mensual por cada menor asilado...Esta cuota resultará mínima si se compara con lo que el Estado debe gastar por cada uno de los menores asilados en los Establecimientos

\footnotetext{
${ }^{30}$ Los suscriptores eran quienes se habían comprometido a entregar en forma regular una suma determinada para sostener las obras salesianas. Sus nombres eran consignados en el Álbum de Oro de la Comisión, recibían el Boletín Salesiano y eran invitados a los eventos públicos de la congregación. Usualmente, las suscripciones eran de carácter anual y para la obra en general, a diferencia de las becas que estaban destinadas al sostenimiento de alumnos.

${ }^{31}$ La mencionada ley, dictada el 21 de octubre de 1919 con apoyo del entonces presidente Hipólito Yrigoyen, instituyó el Patronato de Menores, sumando al conjunto de derechos que los padres poseían sobre las personas y los bienes de sus hijos menores las obligaciones que debían guardar para con ellos. Facultaba al Estado a intervenir en la familia, sustrayendo el menor de considerarse que sus padres no cumplían con esas obligaciones. El ejercicio de la patria potestad podía ser suspendido si cualquiera de los progenitores trataba a sus hijos, sin motivo, con excesiva dureza; o si por consecuencia de su ebriedad consuetudinaria, inconducta notoria o negligencia grave, comprometía su salud, seguridad o moralidad.
} 
Oficiales." 32 Esas propuestas de ingresos de menores a cambio de una contraprestación monetaria se extendían al sur del país ya que, como se consignaba en un informe de la subcomisión Misiones de la Patagonia: "Creen los misioneros que aportando a los hijos de aborígenes los beneficios de la ley No. 10.905 de Patronato de Menores, la asimilación metódica de ese elemento estaría asegurada." 33

A diferencia de las becas, en las entradas de los balances referidas a los subsidios se puede especificar sin dudas la fuente del dinero, que en su mayor parte era el Estado Nacional, aunque se registraron un subsidio municipal en 1919 (de 500 pesos moneda nacional) y dos provinciales en 1923 y 1928 (de 2000 pesos cada uno) cuyos montos fueron exiguos si se comparan con los nacionales (de 24.500 y 305.778 pesos respectivamente). También los egresos son más fácilmente identificables pues las partidas más grandes tenían destinos prefijados: los asilos, colegios, hospitales e iglesias de los territorios nacionales de La Pampa, Río Negro y Chubut. Debido a su lejanía en términos geográficos y a su tardía incorporación efectiva al territorio nacional el Estado enfrentó dificultades para atender todas las demandas educativas y sanitarias de la población residente en ellos, así como para moralizarla y homogeneizarla culturalmente. En consecuencia, la presencia de los religiosos y las religiosas en esas zonas se vio favorecida y fue destinataria desde el siglo XIX de dinero estatal para, entre otras cosas, alojar a menores y mujeres delincuentes. ${ }^{34}$

La concepción de la relación entre la congregación -representada en este caso por las cooperadoras- y el ámbito estatal en términos de colaboración y complementariedad aparecía en los escritos de las autoridades de la Comisión, así como también en los discursos de religiosos publicados en los informes. Estas expresiones se acompañaban con información numérica, tanto acerca del ahorro que significaba para los erarios públicos provinciales y nacional la obtención de fondos privados por parte de la Comisión como de la cantidad de menores abandonados acogidos en los establecimientos, ya fuera trasladados de instituciones oficiales de la Capital o recogidos por los jueces y la policía en los propios territorios nacionales. Con esto se procuraba demostrar la eficacia de la acción “...nacionalizadora, cristiana y social..” que realizaban “...desde Bahía Blanca al Extremo Sur del Continente y desde el Océano Atlántico a las crestas Andinas". 35

Aunque el Estado nunca reconoció el Vicariato y la Prefectura Apostólica tramitada por la congregación con la Santa Sede, sus integrantes ostentarían por largo tiempo una situación preponderante respecto de las misiones y la instrucción católica, a lo cual se

\footnotetext{
32 "Nota de la Presidenta de la Comisión Central de Señoras Cooperadoras a José Camilo Crotto", La Plata, 21 de marzo de 1921, en ACS.

33 Junta Cooperadora de Señoras. Misiones Salesianas de la Patagonia, "Breve Informe", 1924, en Archivo Salesiano Patagónico (ASP), Bahía Blanca-Argentina, pp. 33-34.

${ }^{34}$ Por ejemplo, en 1888 se aprobó un subsidio de \$ 20.000 para el Colegio Pío IX, desde 1893 la congregación recibía los beneficios de la Lotería y desde 1894 se le otorgaba un monto mensual a cambio del asilo y custodia de menores y mujeres delincuentes en sus establecimientos sureños. Ministerio de Justicia e Instrucción Pública de la Nación Argentina, Exp.-C-34/903, Buenos Aires, 27 de enero de 1903, en ASP. Los religiosos habían ingresado a la Patagonia junto con el ejército argentino en 1879. Sobre las primeras acciones de financiamiento estatal a la congregación véase: Landaburu, Niñez, juventud y educación.

35 Junta Cooperadora de Señoras. Misiones Salesianas de la Patagonia, "Breve Informe”, en ASP, p. 29.
} 
sumaban la acción pastoral y la atención de la salud. Cabe aclarar que, pese a los discursos conciliatorios y al apoyo eclesiástico, político y de la propia sociedad, la convivencia entre religiosos y religiosas por un lado, y algunos agentes del Estado como los maestros normalistas y las autoridades del Consejo Nacional de Educación identificados con el laicismo por el otro, no estuvo exenta de conflictos. Además, en el territorio nacional de La Pampa la cuestión del alojamiento de menores y mujeres criminales suscitó problemas entre los jueces y los religiosos que se resistieron a ingresarlos. ${ }^{36}$

En suma, la fase del proceso de sostenimiento que involucraba al área estatal no se desarrolló sin fricciones que involucraron también a la Comisión, ya que en diversas notas, cartas e informes sus dirigentes resaltaban con vehemencia la insuficiencia de los aportes oficiales y solicitaban mayores fondos. A esto se agregaba que las becas y subsidios no siempre se liquidaban en el plazo acordado, lo cual generaba demandas y pedidos de entrevistas a funcionarios, además de complicar las rendiciones de cuentas. Por su parte, las autoridades les exigían completar cuestionarios y confeccionar cuadros estadísticos, lo que tampoco se realizaba siempre dentro de los tiempos esperados, ocasionando reclamos por parte de éstas a los religiosos y las cooperadoras. ${ }^{37}$

Otra fuente de ingresos de la Comisión eran dos grandes colectas que se organizaban anualmente: la del Pan de Cada Día y la de los Hacendados. En la primera de ellas contribuían las cooperadoras de la Comisión, dependencias del Poder Ejecutivo Nacional como el Ministerio de Marina y la Secretaría de la Presidencia, casas comerciales como Harrods, industrias como el Frigorífico Las Palmas, asociaciones como el Jockey Club, órganos periodísticos como Caras y Caretas y La Razón, entre otros benefactores. Browne, que solía estar a cargo de la misma, consignaba en forma manuscrita el detalle de los contribuyentes y el nombre de la cooperadora que había obtenido cada dádiva y realizaba, bajo supervisión de la tesorera, una copia mecanografiada de esa información. Además de las contribuciones monetarias, en esa nómina había donaciones de elementos de higiene y de alimentos como arroz, fideos, aceite y porotos, efectuadas por diferentes fábricas y comercios. Para realizar

\footnotetext{
${ }^{36}$ Para ampliar este tema véase: Ana M. T. Rodríguez, "Las leyes laicas y la Iglesia Católica en los territorios del interior argentino (1884-1920)". Revista Brasileira de História das Religiões Vol. 7, n 19 (2014): 71-90, http://dx.doi.org/10.4025/rbhranpuh.v7i19.23986. En relación al campo educativo patagónico, María Andrea Nicoletti señala que tanto la institución estatal como la religiosa construyeron dos paradigmas homogeneizadores. La Congregación Salesiana buscó la formación de ciudadanos católicos bajo la premisa de civilizar y evangelizar y el Estado nacional, imponiendo la centralización basándose en la legislación sobre los territorios nacionales y la Ley de Educación Común número 1420, quería nacionalizar y argentinizar los territorios para formar honrados ciudadanos, también bajo el prisma de la civilización, pero teniendo en cuenta los principios rectores de laicidad y de progreso. María Andrea Nicoletti, "Formar ciudadanos argentinos y católicos en la Patagonia Norte de los Territorios Nacionales: la Congregación Salesiana y las escuelas del Estado (1880-1950)". Boletín Americanista Año LXVI. 1, n 72 (2016): 71-88.

${ }^{37}$ Algunos de los documentos que contienen reclamos al respecto son los siguientes: "Nota de A. Hudson a la Presidenta de la Comisión Cooperadora Salesiana", Buenos Aires, 18 de octubre de 1921, en ACS; "Nota del Ministerio de Relaciones Exteriores y Culto a la Presidenta de la Comisión Central de Señoras Cooperadoras Salesianas", Buenos Aires, 30 de septiembre de 1925, en ACS; "Nota del Departamento de Relaciones Exteriores y Culto a la Presidenta de la Comisión Central de Señoras Cooperadoras Salesianas", Buenos Aires, 20 de diciembre de 1928, en ACS; "Nota del Departamento de Relaciones Exteriores y Culto a la Comisión Central de Señoras Cooperadoras", Buenos Aires, 11 de octubre de 1929, en ACS.
} 
la colecta de los Hacendados, que en la mayor parte del periodo superó en recaudación a la primera, ${ }^{38}$ se enviaban cartas a los potenciales benefactores, como la dirigida a Diego de Alvear en 1921, en la cual se le recordaba que había colaborado en años anteriores con esta iniciativa y se invocaba el nombre de su madre, que había sido la primera presidenta honoraria de la Comisión. ${ }^{39}$

A las colectas descriptas se sumaban otras de menor envergadura, como las realizadas periódicamente en las reuniones de la Comisión o las instrumentadas a través de las "cajas de centavos" en domicilios particulares. ${ }^{40}$ También se agregaban algunas extraordinarias, como la que se efectuó con el objeto de reunir fondos para construir el Hogar del NiñoInstituto Salesiano Domingo Savio, una iniciativa de las cooperadoras fundada en lo resuelto en el IX Congreso Internacional de Cooperadores Salesianos realizado en 1925. Esa institución sería un internado para niños de entre 8 y 12 años de edad con cursos preparatorios para ingresar a las escuelas de artes y oficios y agricultura. ${ }^{41}$ Algunas familias destacadas de la elite-como las de Browne y Adela María Harilaos- contribuyeron con sumas importantes con la finalidad de que determinados dormitorios se consagraran a la memoria de sus seres queridos. Asociaciones como el Jockey Club y entidades financieras como el Banco de la Nación Argentina y el Banco Hipotecario Nacional se contaron también entre los aportantes para esa fundación.

Las colectas podían insumir varios días y conllevaban una importante labor propagandística que incluía el envío de circulares y la exhibición de afiches en estaciones ferroviarias, teatros, cines, hoteles, tiendas y confiterías. Implicaba una notable presencia pública en las calles de la ciudad y exigía una articulación con otros actores de la congregación, como los cooperadores, exalumnos y exalumnas. Tanto los religiosos como las autoridades de la Comisión celebraban la participación de las cooperadoras en esta modalidad de recaudación que ponía de relieve las redes de relaciones construidas entre la elite y la congregación.

Otra categoría de ingresos era la de donaciones, que contaba con ciertos aportes monetarios regulares para la obra de las cooperadoras en general, ya fuera de particulares como Leonor Uriburu que entregaba anualmente 200 pesos moneda nacional, o de entidades como el Jockey Club que entregó, por ejemplo, 10.000 pesos en 1919 y 5000 en 1920 y 1921. No eran inusuales las dádivas personales de las integrantes de la Comisión, que contribuían con su peculio para la construcción y ensanche de determinados establecimientos como la

\footnotetext{
${ }^{38}$ Por ejemplo, al inicio de la década de 1920 la amplitud entre ambas fue muy amplia, probablemente por la recuperación económica del sector agroexportador luego de la posguerra. Mientras que en 1919 la primera recaudó 5.223 pesos moneda nacional y la segunda 8.353; en los dos años posteriores las cifras de la primera se mantuvieron estables (5.447 y 5.117 pesos), mientras que las de la segunda ascendieron considerablemente (a 15.193 y 27.775 pesos respectivamente).

39 “Carta de la Comisión Central de Señoras Cooperadoras Salesianas a Diego de Alvear”, Buenos Aires, 16 de noviembre de 1921, en ACS.

${ }^{40}$ Los ingresos obtenidos por estas vías eran muy reducidos. Por ejemplo, en 1924 se recaudaron solo 64 pesos a través de alcancías.

${ }^{41}$ La piedra fundamental se colocó en noviembre de 1925, las obras comenzaron en agosto de 1928 y en septiembre de 1930 comenzaron a llegar los primeros alumnos.
} 
Escuela taller de Maldonado -que estaba a cargo de las religiosas de María Auxiliadora- o el Hogar del Niño. A partir de 1925 muchos donantes esporádicos señalaron a esta obra como destino específico de su contribución, como Maria Duprat que entregó dinero en cuotas para la construcción de un salón en memoria de la nieta Sara María Lagarde e Inés Dorrego que hizo lo propio en recuerdo de Enriqueta L. de Dorrego. El monto más importante fue entregado por Catalina Barón en persona y luego de su fallecimiento por sus herederos. ${ }^{42}$

Cabe advertir que, como señalamos para otros rubros de ingresos, había más donaciones a la congregación que no eran vehiculizadas a través de la Comisión, aunque es innegable que ésta tenía un rol relevante en su consecución. En la segunda mitad de la década de 1920 escribir cartas de petición de donaciones a casas exportadoras, instituciones bancarias, comercios, fábricas, etc., era una práctica regular, como lo demuestra la gran cantidad de copias de estas misivas y de respuestas de los destinatarios que fueron archivadas. Si bien no todos los pedidos recibían contestaciones favorables, muchos interpelados se mostraron predispuestos a colaborar pecuniariamente o entregando mercadería. ${ }^{43}$

Finalmente, otros ingresos procedían de los eventos y las rifas, actividades que, como las descriptas precedentemente, debían programarse con aprobación del inspector. Los primeros estaban a cargo de una subcomisión denominada "Comisión Auxiliar de Fiestas" e incluían veladas artísticas, fiestas y actividades infantiles. Los magros resultados obtenidos por su intermedio, sumados a la dificultad de organizar reuniones que se encuadraran dentro de la moral católica, condujeron a que quienes la integraban colaboraran en otro tipo de tareas y a que hacia fines de la década del veinte se quitara de su nombre la calificación "de Fiestas". ${ }^{44}$ La subcomisión creada en 1920 para patrocinar los emprendimientos patagónicos continuó organizando algunos eventos pero de otro tenor, ya que mayormente eran exposiciones y ventas de los trabajos realizados en los colegios, y otra subcomisión auxiliar constituida en Mar del Plata en 1928 llevó adelante la Semana de Don Bosco en esa ciudad, actividad contribuyó a reunir la mayor parte de los 23238 pesos moneda nacional consignados en el cuadro comparativo para ese año. En cuanto a las rifas, incluyeron collares donados por la señora de Iriondo en 1908 y 1914 -uno de ellos para levantar en el taller de María Auxiliadora de Maldonado un salón en memoria de la señora Mercedes Zavala de

\footnotetext{
42 "Carta de Leonor Uriburu a Carmen Alvear", Buenos Aires, 12 de septiembre de 1927, en ACS; "Carta de Esteban Pagliere a Carmen Alvear", Buenos Aires, 14 de diciembre de 1928, en ACS; Comisión Central de Señoras Cooperadoras Salesianas, "Balance", Buenos Aires, 1923, en ACS; "Informe General de la Comisión Central de Señoras Cooperadoras", en ACS; "Carta de María Duprat a la Comisión Central de Señoras Cooperadoras Salesianas", Buenos Aires, 18 de diciembre de 1925, en ACS; "Carta de Inés Dorrego a Esteban Pagliere", s.l., 20 de enero de 1928, en ACS.

${ }^{43}$ Entre ellos podemos listar a los siguientes: Cámara Gremial de Cereales de la Bolsa de Comercio, Bunge \& Born, Dreyfus y cía , Ernesto Tornquist y cía, Cervecería Quilmes, E. Palavicini y cía, Piccardo y cía, Weil Hnos y cía, Gath \& Chaves, Harrods, Banco de la Provincia de Buenos Aires, Banco el Hogar Argentino, Banco Argentino Uruguayo, Banco Popular Argentino, Banco Hipotecario Nacional, Banco Español del Río de la Plata, Nuevo Banco Italiano, Banco de Londres y América del Sud, Banco Holandés de la América del Sud, The First National Bank of Boston y Jockey Club.

44 "Informe de la Comisión de Señoras Cooperadoras Salesianas presentado en la asamblea del 8 de noviembre de 1920", Buenos Aires, 1920, en ACS, p. 15.
} 
Iriondo-, un collar y pendantif en 1917, un collar de perlas -también en beneficio de la obra de las hermanas-en 1920 y un bargueño antiguo y una lámpara votiva de plata boliviana en febrero de 1923, todos estos últimos de origen no registrado. ${ }^{45}$

En cuanto al análisis cuantitativo de la evolución de los ingresos y los egresos, los balances exhiben una considerable heterogeneidad en la nomenclatura contable, que se manifiesta tanto en la inexistencia de un criterio único para designar las partidas y, eventualmente, en la falta de especificidad, como en la utilización de diferentes categorías para dar cuenta de las mismas partidas. Pese a esta irregularidad formal, pueden sistematizarse las entradas para obtener un panorama panorama ligero de su desarrollo, realizando una inspección pormenorizada de las diferentes partidas y cotejando su contenido con información auxiliar, pero no así los egresos, ya que el grado de heterogeneidad es mayor en esas columnas. Una causa de esto podría ser la superposición de las diferentes lógicas geográfico-administrativas del Estado Nacional, los religiosos, las religiosas y la Comisión Central. Estos actores tenían diseños organizativos divergentes y que, además, no fueron estables en el periodo analizado. ${ }^{46}$ Esto generó cierta dispersión en la adjudicación del dinero que se plasmó en esos segmentos de los balances, generando inconvenientes metodológicos para agregarlos en categorías unificadoras y comparables a lo largo del tiempo. Sin embargo, a grandes rasgos puede señalarse que en su mayor parte se entregaban a religiosos, el resto a religiosas y una minima porción se reservaba para el costeo de gastos administrativos de la Comisión.

Si analizamos la evolución de las fuentes de ingresos desde la transición hacia la década del veinte hasta fines de la misma (Figura 3$)^{47}$ observamos que las becas y suscripciones mantuvieron valores relativamente estables, mientras que desde 1922 se registró un incremento del monto correspondiente a los subsidios para territorios nacionales y menores, el cual se acentuó de manera considerable hacia el final del periodo llegando a representar la mayor parte del total de ingresos. En esto se vislumbra un progresivo interés del Estado por continuar solventando la obra salesiana particularmente en la Pampa y la Patagonia. Cabe destacar que la intención de provisión de recursos por parte del Estado fue aún mayor a la que graficamos ya que, si bien no llegaron a cobrarse porque la obra se

\footnotetext{
45 Comisión de Cooperadoras Salesianas, “Apuntes del libro de Actas", Buenos Aires, 1907-1922, en ACS; "Acta de rifa", Buenos Aires, 1920, en ACS; "Acta de rifa", Buenos Aires, 21 de octubre de 1923, en ACS.

${ }^{46}$ Sobre la organización de las religiosas véase: Olga Tarrasa, Reseña histórica de cada comunidad. Desde los inicios hasta el año 2000 (Bahía Blanca: Instituto María Auxiliadora, Inspectoría San Francisco Javier, s..f.).

${ }^{47}$ Los datos se presentan en términos nominales, expresados en pesos moneda nacional. Desde 1918 hubo una relativa estabilidad monetaria siendo muy baja la inflación promedio (de aproximadamente medio punto porcentual anual promedio, lo que determinó un nivel de precios promedio en el período alrededor de un $7 \%$ superior al nivel de 1917). Sin embargo, se alternaron años inflacionarios y deflacionarios. En los primeros años se sucedieron varias tasas de inflación altas —el máximo acumulado se alcanzó en 1920: 38\% en tres años y la mayor variación positiva fue de $23 \%$ en 1918 - . Sin embargo una serie de años deflacionarios hizo que el período se cerrara (entre 1926 y 1930) con un nivel de precios alrededor de tres puntos inferior al nivel de 1917. Los datos de inflación provienen del archivo INDICERA (http://www.anav.org.ar/sites_personales/5/), que recopila diversas mediciones históricas. Se utilizaron los niveles de precios al consumidor del Instituto Nacional de Estadísticas y Censos de la República Argentina. Se tomaron precios al consumidor por el tipo de gasto que hacía la congregación salesiana.
} 
encontraba en construcción, desde 1925 figuraban en el presupuesto partidas de $\$ 5000$ anuales con orden de pago para el mantenimiento del Hogar del Niño. ${ }^{48}$

\section{Figura 03. Gráfico de la evolución de los ingresos de la Comisión Central de Señoras Cooperadoras Salesianas}

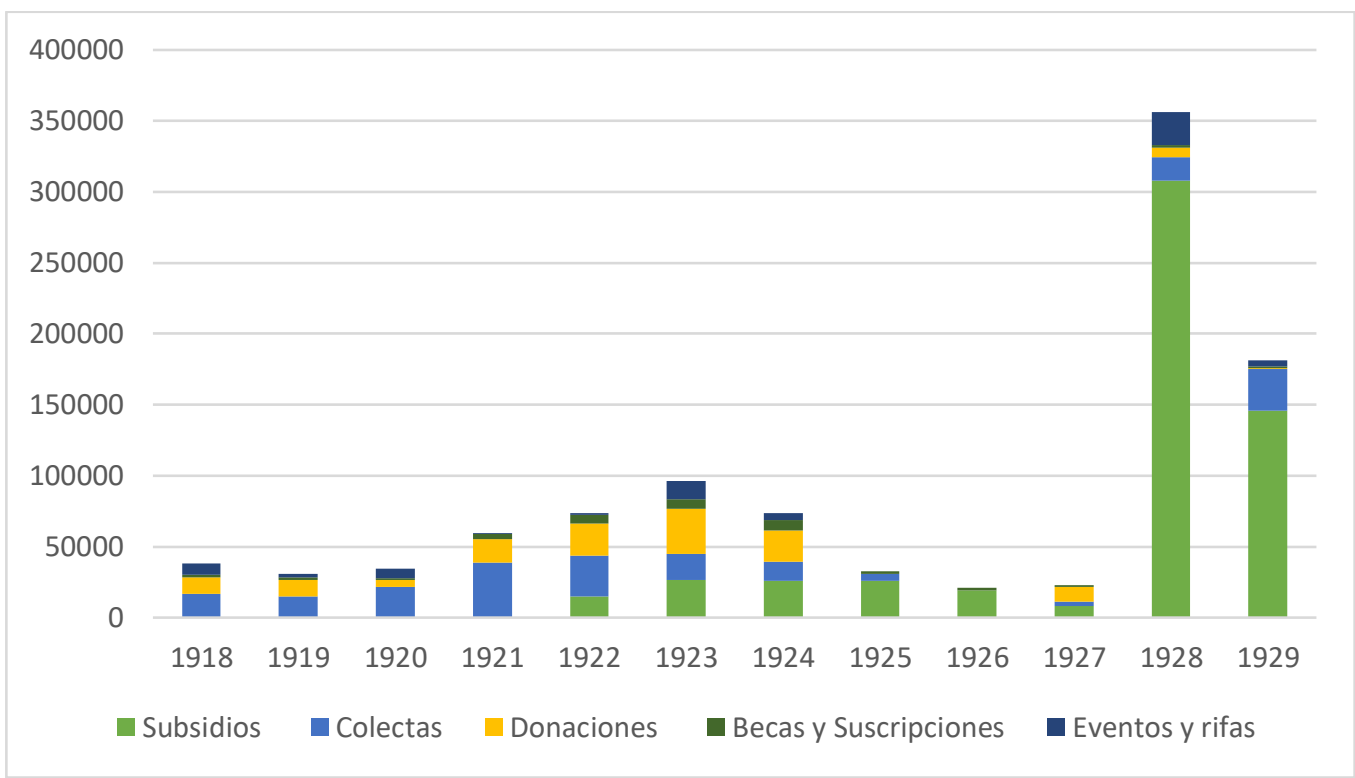

Fuente: elaboración propia en base a ACS, Balances de la Comisión Central de Señoras Cooperadoras Salesianas, Buenos Aires, 1918-1929.

En el tema de la minoridad convergían las preocupaciones estatales con las de los religiosos, las religiosas, las cooperadoras y la elite, como se aprecia en el hecho que las donaciones, que decrecieron luego de un aumento considerable en los tres primeros años de la década del 1920, volvieron a aumentar en 1927 debido a las contribuciones destinadas al Hogar del Niño. En cuanto a las colectas, según lo que puede observarse en el gráfico, también experimentaron un decrecimiento en esa década, luego de un pico máximo en 1923, que se mantuvo hasta los dos últimos años del periodo en los que se registró un nuevo aumento coincidiendo con la promoción dada a ese proyecto de albergue y formación infantil. A esto debe agregarse que se produjo una gran acentuación de la recaudación por rifas y eventos en 1928, fenómeno que no se vislumbraba desde los primeros años de la década. Cabe destacar que a las importantes sumas de origen particular en estos rubros se añadían también algunas estatales, evidenciando que el dinero oficial no se ceñía únicamente a las secciones de becas y subsidios.

En relación con lo anterior, cabe aclarar que el nulo aporte de la colecta en el año 1926 como así también la falta de donaciones entre 1925 y 1927 no respondieron a una

\footnotetext{
48 "Notas del Departamento de Relaciones Exteriores y Culto dirigidas a la Comisión de Señoras Cooperadoras Salesianas", Buenos Aires, 1925, 1928 y 1929, en ACS.
} 
disminución real, sino a la ausencia de registro en los balances de la Comisión Central. Esto se debió a que en 1926 se independizó la subcomisión destinada a atender los emprendimientos patagónicos y, como consecuencia, a partir de allí no se consignó lo recaudado por ésta, lo cual explica el decrecimiento o falta de algunas fuentes de ingresos. Dicho nucleamiento, si bien se autonomizó, continuó radicado en la Capital Federal, por lo cual sus fuentes de recaudación eran las mismas que las de las de la comisión primigenia y lo obtenido fue volcado en balances propios. ${ }^{49}$

El análisis de la evolución de las entradas a partir del gráfico muestra también que desde 1926, pese al recorte de su radio de acción, la Comisión Central continuó patrocinando colegios de la Inspectoría San Francisco Solano y cobrando los subsidios para los territorios nacionales de Chubut y Río Negro que integraban la Inspectoría San Francisco Javier. Como ya señalamos, los montos de estos últimos tenían una magnitud tal que los erigía en una herramienta importante, tanto desde el punto de vista material como desde el simbólico - por la significación que tenía para la congregación la evangelización del sur argentino-, para quienes los recaudaran y distribuyeran. Al producirse el desmembramiento de la Comisión Central un punto de disputa entre las presidentas fue precisamente el criterio de reparto de los subsidios destinados a los territorios nacionales. ${ }^{50}$

Al tratar de desentrañar los factores que motivaron la continuidad de dichas asignaciones a la Comisión Central surge uno de orden práctico, vinculado con que el dinero de los subsidios para los territorios nacionales era liquidado en bloque, sin discriminar el de La Pampa (que sí integraba la Inspectoría San Francisco de Sales), a través de un cheque a la orden de la presidenta. Sin embargo, debe considerarse también que la trayectoria de la Comisión, que había sido el primer agrupamiento femenino del país, así como el adjetivo de "Central" que continuó manteniendo, le permitieron adquirir preeminencia sobre los otros grupos de cooperadoras, aunque de acuerdo con la normativa éstos eran autónomos, ya que funcionaban en la órbita de las casas en las que se constituían y bajo la autoridad de sus correspondientes directores. Pese a que lo intentaron, las cooperadoras que integraban la Comisión Central no lograron mantener bajo su órbita a la subcomisión abocada a recaudar dinero para la zona sureña, pero no le transfirieron el manejo de los subsidios, un resorte fundamental para financiar las actividades de la congregación en el sur del país y que constituía el nudo de su relación con el Estado.

\section{Consideraciones finales}

Desde su condición de "damas" pertenecientes a sectores sociales de elite, ligadas a sectores dirigentes por lazos de parentesco y amistad y con una situación económica acomodada, aunque con un status jurídico subordinado y tuteladas por religiosos, las cooperadoras

\footnotetext{
${ }^{49}$ En trabajos próximos analizaremos los informes y balances de esta entidad.

${ }^{50}$ Estos conflictos han sido analizados en Lucía Bracamonte, "Un conflicto plasmado en cartas: convergencias y divergencias entre sacerdotes y cooperadoras salesianas. Argentina (1920-1926)". Revista Cultura \& Religión Vol. $12, \quad \mathrm{n}^{\circ} \quad 1 \quad$ (2018): https://www.revistaculturayreligion.cl/index.php/culturayreligion/article/view/804.
} 
participaron en la esfera pública a partir de su inserción en un espacio de sociabilidad de tinte religioso e interactuando con la esfera estatal. Su capacidad para obtener recursos movilizando influencias y generando redes de benefactores y de colaboradores fue reconocida y elogiada por los religiosos. Aportaron dinero a la congregación consiguiendo suscripciones, organizando colectas, rifas y eventos, y tramitando becas y subsidios, así como también donando parte de su propio dinero o bienes al servicio de los fines que perseguían. Si bien la extracción social de las dirigentes, los métodos de recaudación y la justificación maternalista de las actividades no diferían de los de otras asociaciones benéficas confesionales y laicas conducidas por mujeres, el hecho de estar ligadas formalmente como tercera orden a una congregación y la proyección geográfica de su influencia constituyeron marcas distintivas de su agencia asistencialista.

En la década de 1920, gran parte de los recursos aportados por las cooperadoras provino crecientemente del Estado, lo cual se asentaba sobre una trayectoria de asignación de recursos económicos a la congregación iniciada a fines del siglo XIX. Esto se debía al ideario liberal que apuntaba a reducir sus funciones y gastos, a la necesidad de argentinizar y de contar con sitios para depositar mujeres delincuentes y especialmente menores, y a la legitimación de la actuación de las benefactoras en el contexto de un sistema mixto de atención de las necesidades sociales. La responsabilidad y el éxito recaudador de las cooperadoras se incrementaron en esa época, en un marco de extensión de la obra salesiana y de consolidación de las concreciones institucionales previas, así como de una progresiva intervención estatal en el área de la minoridad. En ese marco pusieron en juego su propia experiencia de gestión y la de sus predecesoras, adquirida tanto en la Pía Unión como en otras entidades benéficas, y tuvieron una gran influencia sobre las nuevas comisiones que se iban conformando.

Esta complementariedad entre el Estado y la congregación, legitimada por las elites política y social pero no exenta de tensiones, le permitió al primero atender demandas sociales de la población y paliar el déficit de establecimientos para alojar a los menores a través del pago de becas y subsidios, poniendo en práctica la legislación vigente pero sin afrontar el costo de una intervención directa mediante la creación y gestión de mayor cantidad de instituciones correccionales. Todos estos actores coincidían en la necesidad de asistir, moralizar y formar para el trabajo a los futuros ciudadanos y a las futuras madres de la república.

A los religiosos y las religiosas esa acción mancomunada les posibilitó financiar en parte su obra misionera y educadora en permanente expansión sobre amplios sectores sociales, en especial sobre indígenas sometidos, argentinos e inmigrantes de las clases medias y obreras, con foco sobre los jóvenes, niños y niñas. Esto contribuiría a extender la influencia católica tanto en las grandes urbes modernizadas del interior como en las zonas rurales, cuyas proporciones se harían visibles masivamente con posterioridad. Pese a la complejización de la cooperación salesiana femenina en la década de 1920, la Comisión Central continuó jugando un rol importante como articuladora y proveedora de recursos en estos procesos de 
avance católico y estatal que conducirían a la identificación discursiva entre el ser nacional y el catolicismo en el decenio siguiente.

\section{Referencias bibliográficas}

\section{Fuentes primarias Archivo Central Salesiano (ACS), Buenos Aires-Argentina.}

Acta de rifa, Buenos Aires, 1920.

Acta de rifa, Buenos Aires, 21 de octubre de 1923.

Actas del II Congreso Internacional de Cooperadores Salesianos, Buenos Aires, 1900.

Balances de la Comisión Central de Señoras Cooperadoras Salesianas, Buenos Aires, 1918-1929.

Carta de Enriqueta Alais a José M. Vespignani, El Retiro, 30 de mayo de 1916.

Carta de Esteban Pagliere a Carmen Alvear, Buenos Aires, 14 de diciembre de 1928;

Carta de Inés Dorrego a Esteban Pagliere, Buenos Aires, 20 de enero de 1928.

Carta de la Comisión Central de Señoras Cooperadoras Salesianas a Diego de Alvear, Buenos Aires, 16 de noviembre de 1921.

Carta de Leonor Uriburu a Carmen Alvear, Buenos Aires, 12 de septiembre de 1927.

Carta de María Duprat a la Comisión Central de Señoras Cooperadoras Salesianas, Buenos Aires, 18 de diciembre de 1925.

Carta de Sor Josefina Picardo a Carmen Alvear, Viedma, 29 de septiembre de 1928.

Carta de S.S.C y C. a Julia Coy, Buenos Aires, 23 de noviembre de 1929.

ACS, Carta de S.S.S. y C. a Celia Lapalma, Buenos Aires, 24 de diciembre de 1920.

Comisión de Cooperadoras Salesianas Apuntes del libro de Actas, Buenos Aires, 1907-1922.

Comisión Central de Sras. Cooperadoras Salesianas, Invitación, 15 de junio de 1920.

Informe General de la Comisión Central de Señoras Cooperadoras, Buenos Aires, 1927-1929.

José M. Vespignani, Reglamento General de la Comisión Central de Señoras Cooperadoras Salesianas de Buenos Aires, s.f.

Manual teórico-práctico para uso de los decuriones y directores de la Pía Asociación de los cooperadores salesianos, Turín, Tipografía Salesiana, 1897.

Nota de la Presidenta de la Comisión Central de Señoras Cooperadoras a José Camilo Crotto, La Plata, 21 de marzo de 1921.

Nota de A. Hudson a la Presidenta de la Comisión Cooperadora Salesiana, Buenos Aires, 18 de octubre de 1921.

Nota del Ministerio de Relaciones Exteriores y Culto a la Presidenta de la Comisión Central de Señoras Cooperadoras Salesianas, Buenos Aires, 30 de septiembre de 1925.

Nota del Departamento de Relaciones Exteriores y Culto a la Presidenta de la Comisión Central de Señoras Cooperadoras Salesianas, Buenos Aires, 20 de diciembre de 1928.

Nota del Departamento de Relaciones Exteriores y Culto a la Comisión Central de Señoras Cooperadoras, Buenos Aires, 11 de octubre de 1929.

Programa de la Comisión Auxiliar de Señoras Cooperadoras, Buenos Aires, s. f.

Archivo Salesiano Patagónico (ASP), Bahía Blanca-Argentina.

Ministerio de Justicia e Instrucción Pública de la Nación Argentina, Exp.-C-34/903, Buenos Aires, 27 de enero de 1903.

Junta Cooperadora de Señoras. Misiones Salesianas de la Patagonia, Breve Informe, 1924.

\section{Texto inédito}

Celia Lapalma de Emery, Acción pública y privada en favor de la mujer y del niño en la República Argentina, Buenos Aires, Alfa y Omega, 1910. 


\section{Fuentes secundarias}

Bracamonte, Lucía. "Un conflicto plasmado en cartas: convergencias y divergencias entre sacerdotes y cooperadoras salesianas. Argentina (1920-1926)". Revista Cultura \& Religión Vol. 12, n 1 (2018): 28-53, https://www.revistaculturayreligion.cl/index.php/culturayreligion/article/view/804.

Cobo Bedia, Rosa. "Otro recorrido por las ciencias sociales: género y teoría crítica". En Cuadernos de género: Políticas y acciones de género, editado por Marta Aparicio García et al. Madrid: Universidad Complutense, 2009, 11-36.

Di Stefano, Roberto y Aliocha Maldavsky. Invertir en lo sagrado: salvación y dominación territorial en América y Europa: siglos XVI-XX. Santa Rosa: Universidad Nacional de La Pampa, 2018.

Guy, Donna J. Las mujeres y la construcción del Estado de Bienestar. Caridad y creación de derechos en Argentina. Buenos Aires: Prometeo Libros, 2011.

Landaburu, Alejandra. Niñez, juventud y educación. El proyecto salesiano en Tucumán. 1916-1931. Tucumán: Edunt, 2012.

Lida, Miranda. Historia del catolicismo en la Argentina entre el siglo XIX y el XX. Buenos Aires: Siglo Veintiuno Editores, 2015.

Losada, Leandro. La alta sociedad en la Buenos Aires de la Belle Epoque. Buenos Aires: Siglo XXI, 2008.

Mallimaci, Fortunato. El mito de la Argentina laica. Catolicismo, política y Estado. Buenos Aires: Capital Intelectual, 2015.

Moretti, Nicolás D. Buenos cristianos y honrados ciudadanos. La obra salesiana y la cuestión social. Córdoba, 1905-1930. Córdoba: CEH, 2014.

Moreyra. Beatriz I. "Modelo asistencial e historiografía en Argentina en la modernidad liberal". Quinto Sol Vol. 21, n 3 (2017): 1-25, http://dx.doi.org/10.19137/qs.v21i3.1448.

Moreyra, Beatriz I. "La cuestión social y las instituciones de protección social en la modernidad liberal: una relectura hermenéutica de las fuentes institucionales". En Las fuentes documentales en la historia social latinoamericana, compilado por Fernando J. Remedi. Córdoba: Centro de Estudios Históricos Prof. Carlos S.A. Segreti, Red Internacional de Historia Social, 2015.

Nicoletti, María Andrea. "Formar ciudadanos argentinos y católicos en la Patagonia Norte de los Territorios Nacionales: la Congregación Salesiana y las escuelas del Estado (1880-1950)". Boletín Americanista Año LXVI. 1, $\mathrm{n}^{\circ} 72$ (2016): 71-88.

Nicoletti, María Andrea. "La Patagonia como territorio en disputa: tensiones entre el Estado, la Iglesia y la Congregación salesiana por el espacio misionero". Revista Cultura y Religión Vol. VI, nº 1 (2012): 183-203, https://core.ac.uk/download/pdf/158834355.pdf

Nicoletti, María Andrea e Iván Ariel Fresia. "Breve relación de las misiones de la Patagonia hecho el 29 setiembre de 1887. El militarismo patagónico. El General Villegas por el salesiano Antonio Ricardi”. Corpus Año 4, n 1 (2014): s.p., http://corpusarchivos.revues.org/688.

Pita, Valeria Silvina. "Política, conflictos y consensos en torno al brazo asistencial del Estado argentino. La Sociedad de Beneficencia de la Capital, 1880-1910.”. En Mujeres y Asistencia Social en Latinoamérica, siglos XIX y XX. Argentina, Colombia, México, Perú y Uruguay, compilado por Yolanda Eraso. Córdoba: Alción, 2009.

Rodríguez, Ana M. T. "Las leyes laicas y la Iglesia Católica en los territorios del interior argentino (18841920)". Revista Brasileira de História das Religiões Vol. 7, $\mathrm{n}^{\circ} 19$ (2014): 71-90, http://dx.doi.org/10.4025/rbhranpuh.v7i19.23986

Ruffini, Martha. La pervivencia de la República posible en los territorios nacionales. Poder y ciudadanía en Río Negro. Bernal: Universidad Nacional de Quilmes Editorial, 2007.

Tarrasa, Olga. Reseña histórica de cada comunidad. Desde los inicios hasta el año 2000. Bahía Blanca: Instituto María Auxiliadora, Inspectoría San Francisco Javier, s..f.

Tossounian, Cecilia. "Las Asociaciones Femeninas y la Emergencia de un Estado Social: La Protección a la Maternidad y a la Infancia (Buenos Aires 1920-1940)". Estudios Sociales del Estado Vol. 1/2 (2015): 58-93, http://estudiossocialesdelestado.org/index.php/ese/article/view/56 